\title{
On the Relationship Between Supply Chain and Transportation Network Equilibria: A Supernetwork Equivalence with Computations
}

\author{
Anna Nagurney \\ Department of Finance and Operations Management \\ Isenberg School of Management \\ University of Massachusetts \\ Amherst, Massachusetts 01003 \\ November 2004; revised February 2005 \\ Appears in Transportation Research E 42 (2006) pp. 293-316.

\begin{abstract}
In this paper, we consider the relationship between supply chain network equilibrium and transportation network equilibrium. We demonstrate that a supply chain network equilibrium model introduced earlier can be reformulated as a transportation network equilibrium model with elastic demands through a supernetwork reformulation of the former. This equivalence allows us to transfer the wealth of methodological tools developed for transportation network equilibrium modeling, analysis, and computation to the study of supply chain networks. To illustrate the power of the results, we then apply an algorithm developed for the solution of transportation network equilibrium problems with elastic demands to compute the product shipments and demand market prices in several numerical supply chain network examples taken from the existing literature.
\end{abstract}

Keywords: Supply chain networks; Traffic network equilibrium; Supply chain network equilibrium; User-optimization; Supernetworks; Variational inequalities

Tel.: +1-413-545-5635; fax: +1-413-545-3858.

E-mail address: nagurney@gbfin.umass.edu 


\section{Introduction}

In 2002, Nagurney, Dong, and Zhang proposed (apparently the first) supply chain network equilibrium model in which manufacturers, retailers, and consumers were located at distinct nodal tiers of the network. These decision-makers could compete within a tier but needed to cooperate between tiers so that the commodity/product flows could proceed via transactions from the producers/manufacturers to the consumers who were located at distinct demand markets. The authors modeled the behavior of the various decision-makers and assumed that both manufacturers and retailers were profit-maximizers. The consumers sought to obtain the product at the demand markets such that the price of the product at the retailer plus the incurred transaction cost did not exceed the price that consumers were willing to pay for the product. The governing equilibrium conditions for the complete supply chain were then formulated as a variational inequality. Qualitative analysis was conducted and an algorithm proposed which decomposed the network problem into simple subproblems that allowed for explicit, closed form solutions of the product flows and prices at each iteration.

This model has been used to-date as the foundation for the introduction of electronic commerce into this setting and the introduction of risk and uncertainty (cf. Nagurney et al. (2002), Dong, Zhang, and Nagurney (2004), and the references therein). It has also been instrumental in yielding supply chain network perspectives for other application areas, including recycling, notably, electronic recycling networks (see Nagurney and Toyasaki (2005)), as well as power/electric grid networks consisting of suppliers, generators, distributors, transmitters, and consumers (Nagurney and Matsypura (2004)).

The topic of transportation network equilibrium, on the other hand, has a much longer history than that of supply chain networks, and appears as early as in the work of Kohl (1841) and Pigou (1920), with the first rigorous mathematical treatment given by Beckmann, McGuire, and Winsten (1956) in their classical book. Other seminal publications in terms of transportation network equilibrium modeling and methodological contributions include those of Dafermos and Sparrow (1969), Evans (1976), Smith (1979), Dafermos (1980, 1982), and Boyce et al. (1983). For additional research highlights in transportation network equilibrium, see the paper by Boyce, Mahmassani, and Nagurney (2004) as well as that of Florian and Hearn (1995) and the books by Patriksson (1994) and Nagurney (1999, 2000). 
In supply chain modeling and analysis (cf. Federgruen and Zipkin (1986), Federgruen (1993), Lee and Billington (1993), Slats et al. (1995), Anupindi and Bassok (1996), Bramel and Simchi-Levi (1997), Lederer and Li (1997), Stadtler and Kilger (2000), Miller (2001), Mentzer (2001), Hensher, Button, and Brewer (2001) and the references therein), one, typically, associates the decision-makers with the nodes of the multitiered supply chain network. In transportation networks, on the other hand, the nodes represent origins and destinations as well as intersections. Travelers or users of the transportation networks seek, in the case of user-optimization (cf. Wardrop (1952), Beckmann, McGuire, and Winsten (1956), and Dafermos and Sparrow (1969)), to determine their cost-minimizing routes of travel. The "gaming" or competition on a transportation network takes place on paths associated with origin/destination pairs of nodes whereas that in the supply chain networks takes place on the nodes and links.

This paper is organized as follows. In Section 2, we recall the supply chain network equilibrium model of Nagurney, Dong, and Zhang (2002) and we provide new alternative variational inequality formulations of the governing equilibrium conditions. In Section 3, we review the transportation network equilibrium model with elastic demands of Dafermos and Nagurney (1984), which was also studied by Nagurney and Zhang (1996).

We then, in Section 4, construct the supernetwork equivalence of the supply chain network equilibrium model, which corresponds to a special network configuration of the traffic network equilibrium model of Section 3. In particular, we establish that the variational inequality formulation in link flows, travel demand, and travel disuitilities corresponding to the traffic network configuration revealed through the supernetwork coincides with a novel variational inequality formulation of the supply chain network equilibrium conditions obtained in Section 2. As a consequence, we obtain an entirely new interpretation of the supply chain network equilibrium conditions which correspond to path conditions in the sense of Wardrop (1952). Hence, one advantage of the supernetwork reformulation is that it provides us with path flow information (upon solution) which was not available in the original supply chain network equilibrium formulation(s).

In Section 5, we exploit this connection and apply a discrete-time algorithm developed for the computation of traffic network equilibria and proposed by Nagurney and Zhang 
(1996) to compute solutions to previously solved supply chain network equilibrium numerical examples using the supernetwork representation of the supply chains. The numerical results demonstrate the practical usefulness of the theoretical connections established in this paper between supply chain networks and traffic network problems. Indeed, since, as noted earlier, traffic network equilibrium models and algorithms have evolved over many decades and the state-of-the-art is more advanced than in the case of supply chain networks, the connections established in this paper allow for appropriate algorithms developed for elastic demand traffic networks to now be applied to compute equilibrium solutions to supply chain networks. Also, since equilibria for large-scale traffic networks are regularly computed in practice, the results herein also suggest new opportunities for the effective solution of large-scale supply chain networks.

In Section 6, we present a summary of the results and our conclusions and also provide suggestions for future research, which may include further modeling initiatives that exploit the equivalence established in this paper as well as computational studies. 


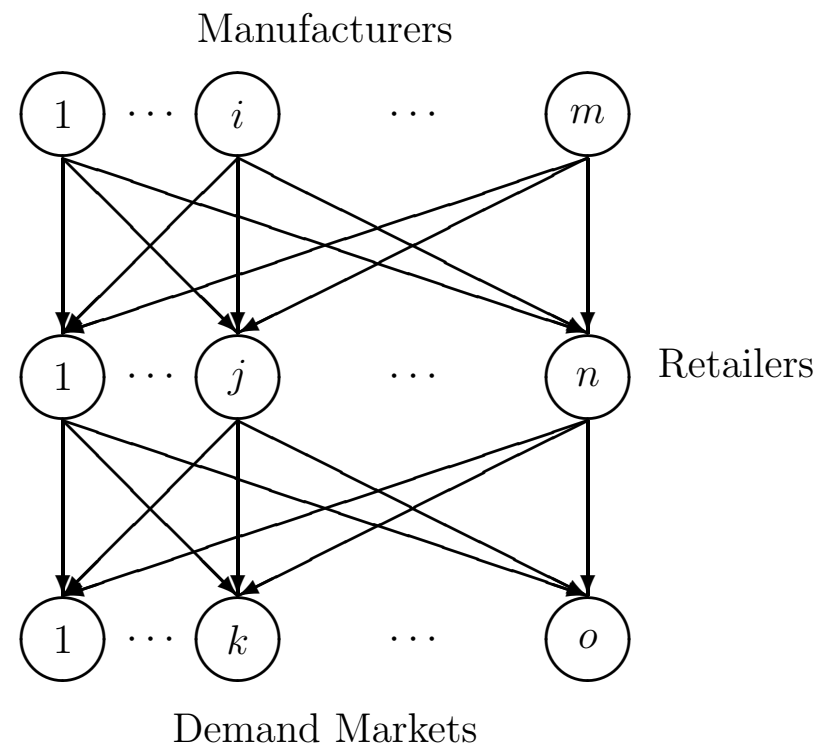

Figure 1: The Network Structure of the Supply Chain at Equilibrium

\section{The Supply Chain Network Equilibrium Model}

In this Section, we recall the supply chain network equilibrium model proposed in Nagurney, Dong, and Zhang (2002). For complete details, we refer the reader to that reference. The model consists of $m$ manufacturers, with a typical manufacturer denoted by $i ; n$ retailers, with a typical retailer denoted by $j$, and consumers associated with $o$ demand markets, with a typical demand market denoted by $k$, as depicted in Figure 1. The manufacturers are involved in the production of a homogeneous product, which can then be purchased by the retailers, who, in turn, make the product available to consumers at the demand markets. The links in the supply chain network denote transportation/transaction links.

For succinctness, we present the notation used for this model in Table 1. All vectors are assumed to be column vectors, except where noted. The equilibrium solution is denoted by "**. 
Table 1: Notation for the Supply Chain Network Equilibrium Model

\begin{tabular}{|l|l|}
\hline Notation & Definition \\
\hline$Q^{1}$ & $\begin{array}{l}\text { vector of the manufacturers' production outputs with components: } q_{1}, \ldots, q_{m} \\
\text { mn-dimensional vector of product shipments between manufacturers } \\
\text { and retailers with component } i j \text { denoted by } q_{i j} \\
\text { no-dimensional vector of product shipments between retailers and demand } \\
\text { markets with component } j k \text { denoted by } q_{j k} \\
n \text {-dimensional vector of shadow prices associated with the retailers } \\
\text { with component } j \text { denoted by } \gamma_{j} \\
\text { o-dimensional vector of demand market prices with component } k \\
\text { denoted by } \rho_{3 k} \\
\rho_{3}\end{array}$ \\
$f_{i}(q) \equiv f_{i}\left(Q^{1}\right)$ & $\begin{array}{l}\text { production cost of manufacturer } i \text { with marginal production cost with respect } \\
\text { to } q_{i} \text { denoted by } \frac{\partial f_{i}}{\partial q_{i}} \text { and the marginal production cost with respect to } q_{i j} \\
\text { denoted by } \frac{\partial f_{i}\left(Q^{1}\right)}{\partial q_{i j}} \\
\text { transaction cost between manufacturer } i \text { and retailer } j \text { with marginal } \\
\text { transaction cost denoted by } \frac{\partial c_{i j}\left(q_{i j}\right)}{\partial q_{i j}} \\
c_{i j}\left(q_{i j}\right)\end{array}$ \\
$s_{j}$ & $\begin{array}{l}\text { vector of the retailers' supplies of the product with components: } s_{1}, \ldots, s_{n} \\
\text { handling cost of retailer } j \text { with marginal handling cost with respect to } s_{j} \\
\text { denoted by } \frac{\partial c_{j}}{\partial s_{j}} \text { and the marginal handling cost with respect to } q_{i j} \text { denoted } \\
\text { by } \frac{\partial c_{j}\left(Q^{1}\right)}{\partial q_{i j}} \\
\text { unit transaction cost between retailer } j \text { and demand market } k \\
\text { demand function at demand market } k\end{array}$ \\
$c_{j k}\left(Q^{2}\right)$ \\
$d_{k}\left(\rho_{3}\right)$
\end{tabular}


We now, for definiteness, recall the behavior of the manufacturers, the retailers, and the consumers associated with the demand markets. We then state the supply chain network equilibrium conditions and provide the variational inequality formulation derived in Nagurney, Dong, and Zhang (2002).

\section{The Behavior of the Manufacturers}

Let $\rho_{1 i j}^{*}$ denote the price charged for the product by manufacturer $i$ to retailer $j$ (i.e., the supply price) and note the conservation of flow equations that express the relationship between the quantity of the product produced by manufacturer $i$ and the associated shipments to the retailers:

$$
q_{i}=\sum_{j=1}^{n} q_{i j}, \quad i=1, \ldots, m .
$$

Due to (1), and as noted in Table 1, we may express the production cost associated with manufacturer $i$, namely, $f_{i}$ as follows: $f_{i}\left(Q^{1}\right) \equiv f_{i}(q)$ for all $i=1, \ldots, m$. We can, thus, express the criterion of profit maximization for manufacturer $i$ as:

$$
\text { Maximize } \sum_{j=1}^{n} \rho_{1 i j}^{*} q_{i j}-f_{i}\left(Q^{1}\right)-\sum_{j=1}^{n} c_{i j}\left(q_{i j}\right)
$$

subject to $q_{i j} \geq 0$, for all $j$.

The first term in (2) represents the revenue and the subsequent two terms the production cost and the transaction costs, respectively, for manufacturer $i$.

We assume that the production cost functions and the transaction cost functions for each manufacturer are continuously differentiable and convex. Hence, as discussed in Nagurney, Dong, and Zhang (2002), assuming that the manufacturers compete in a noncooperative fashion in the sense of Cournot (1838) and Nash $(1950,1951)$, the optimality conditions for

all manufacturers simultaneously (see also Bazaraa, Sherali, and Shetty (1993) and Nagurney (1999)) may be expressed as the following variational inequality: determine $Q^{1 *} \in R_{+}^{m n}$ satisfying:

$$
\sum_{i=1}^{m} \sum_{j=1}^{n}\left[\frac{\partial f_{i}\left(Q^{1 *}\right)}{\partial q_{i j}}+\frac{\partial c_{i j}\left(q_{i j}^{*}\right)}{\partial q_{i j}}-\rho_{1 i j}^{*}\right] \times\left[q_{j}-q_{i j}^{*}\right] \geq 0, \quad \forall Q^{1} \in R_{+}^{m n} .
$$




\section{The Behavior of the Retailers}

The retailers, in turn, are involved in transactions both with the manufacturers since they wish to obtain the product for their retail outlets, as well as with the consumers, who are the ultimate purchasers of the product.

The retailers associate a price with the product at their retail outlets, which is denoted by $\rho_{2 j}^{*}$, for retailer $j$. This price, as discussed in Nagurney, Dong, and Zhang (2002), is determined endogenously in the model along with the prices associated with the manufacturers, that is, the $\rho_{1 i j}^{*}$, for all $i$ and $j$. Assuming, as mentioned in the Introduction, that the retailers are also profit-maximizers, the optimization problem of a retailer $j$ is given by:

$$
\text { Maximize } \rho_{2 j}^{*} \sum_{k=1}^{o} q_{j k}-c_{j}\left(Q^{1}\right)-\sum_{i=1}^{m} \rho_{1 i j}^{*} q_{i j}
$$

subject to:

$$
\sum_{k=1}^{o} q_{j k} \leq \sum_{i=1}^{m} q_{i j}
$$

and the nonnegativity constraints: $q_{i j} \geq 0$, and $q_{j k} \geq 0$, for all $i$ and $k$. Objective function (4) expresses that the difference between the revenues minus the handling cost and the payout to the manufacturers should be maximized. Constraint (5) simply expresses that consumers cannot purchase more of the product from a retailer than is available in stock.

The term $\gamma_{j}$ is the Lagrange multiplier associated with constraint (5) for retailer $j$ and, hence, has an interpretation as a shadow price as noted in Table 1.

We assume that the handling cost for each retailer is continuously differentiable and convex and that the retailers also compete with one another in a noncooperative manner, seeking to determine their optimal shipments from the manufacturers and to the demand markets. The optimality conditions for all retailers simultaneously coincide with the solution of the following variational inequality: determine $\left(Q^{1 *}, Q^{2 *}, \gamma^{*}\right) \in R_{+}^{m n+n o+o}$ satisfying:

$$
\begin{gathered}
\sum_{i=1}^{m} \sum_{j=1}^{n}\left[\frac{\partial c_{j}\left(Q^{1 *}\right)}{\partial q_{i j}}+\rho_{1 i j}^{*}-\gamma_{j}^{*}\right] \times\left[q_{i j}-q_{i j}^{*}\right]+\sum_{j=1}^{n} \sum_{k=1}^{o}\left[-\rho_{2 j}^{*}+\gamma_{j}^{*}\right] \times\left[q_{j k}-q_{j k}^{*}\right] \\
+\sum_{j=1}^{n}\left[\sum_{i=1}^{m} q_{i j}^{*}-\sum_{k=1}^{o} q_{j k}^{*}\right] \times\left[\gamma_{j}-\gamma_{j}^{*}\right] \geq 0, \quad \forall\left(Q^{1}, Q^{2}, \gamma\right) \in R_{+}^{m n+n o+o} .
\end{gathered}
$$




\section{The Consumers at the Demand Markets and the Equilibrium Conditions}

We now describe the behavior of the consumers located at the demand markets. The consumers take into account in making their consumption decisions not only the price charged for the product by the retailers but also the transaction cost to obtain the product.

The consumers take the price charged by the retailers for the product, which, recall was denoted by $\rho_{2 j}^{*}$ for retailer $j$, plus the transaction cost associated with obtaining the product, in making their consumption decisions. The equilibrium condition for consumers at demand market $k$, (cf. Samuelson (1952) and Takayama and Judge (1971)) takes the form: For all retailers $j ; j=1, \ldots, n$ :

$$
\rho_{2 j}^{*}+c_{j k}\left(Q^{2^{*}}\right)\left\{\begin{array}{lll}
=\rho_{3 k}^{*}, & \text { if } & q_{j k}^{*}>0 \\
\geq \rho_{3 k}^{*}, & \text { if } & q_{j k}^{*}=0
\end{array}\right.
$$

and

$$
d_{k}\left(\rho_{3}^{*}\right)\left\{\begin{array}{lll}
=\sum_{j=1}^{n} q_{j k}^{*}, & \text { if } & \rho_{3 k}^{*}>0 \\
\leq \sum_{j=1}^{n} q_{j k}^{*}, & \text { if } & \rho_{3 k}^{*}=0
\end{array}\right.
$$

As discussed in Nagurney, Dong, and Zhang (2002), conditions (7) state that, in equilibrium, if the consumers at demand market $k$ purchase the product from retailer $j$, then the price charged by the retailer for the product plus the unit transaction cost is equal to the price that the consumers are willing to pay for the product. If the price plus the unit transaction cost exceeds the price the consumers are will to pay at the demand market then there will be no transaction between the retailer and demand market pair. Conditions (8) state, in turn, that if the equilibrium price the consumers are willing to pay for the product at the demand market is positive, then the quantities purchased of the product from the retailers will be precisely equal to the demand for that product at the demand market. If the

equilibrium price at the demand market is zero then the shipments to that demand market may exceed the actually demand.

\section{The Equilibrium Conditions of the Supply Chain}

In equilibrium, we must have that the optimality conditions for all manufacturers, the optimality conditions for all retailers, and the equilibrium conditions for all the demand markets, 
must hold simultaneously. Hence, the shipments that the manufacturers ship to the retailers must, in turn, be the shipments that the retailers accept from the manufacturers. In addition, the amounts of the product purchased by the consumers at the demand markets must be equal to the amounts sold by the retailers.

We now state this more formally as done originally in Nagurney, Dong, and Zhang (2002):

\section{Definition 1: Supply Chain Network Equilibrium}

The equilibrium state of the supply chain network is one where: all manufacturers have achieved optimality (cf. (3)); all retailers have achieved optimality (cf. (6)), and, finally, for all pairs of retailers and demand markets, equilibrium conditions (7) and (8) hold.

We now recall the following theorem:

\section{Theorem 1: Variational Inequality Formulation (Nagurney, Dong, and Zhang (2002))}

The equilibrium conditions governing the supply chain network model are equivalent to the solution of the variational inequality problem given by: determine $\left(Q^{1^{*}}, Q^{2^{*}}, \gamma^{*}, \rho_{3}^{*}\right) \in R_{+}^{m n+m+n+o}$ satisfying:

$$
\begin{gathered}
\sum_{i=1}^{m} \sum_{j=1}^{n}\left[\frac{\partial f_{i}\left(Q^{1^{*}}\right)}{\partial q_{i j}}+\frac{\partial c_{i j}\left(q_{i j}^{*}\right)}{\partial q_{i j}}+\frac{\partial c_{j}\left(Q^{1^{*}}\right)}{\partial q_{i j}}-\gamma_{j}^{*}\right] \times\left[q_{i j}-q_{i j}^{*}\right] \\
+\sum_{j=1}^{n} \sum_{k=1}^{o}\left[c_{j k}\left(Q^{2^{*}}\right)+\gamma_{j}^{*}-\rho_{3 k}^{*}\right] \times\left[q_{j k}-q_{j k}^{*}\right]+\sum_{j=1}^{n}\left[\sum_{i=1}^{m} q_{i j}^{*}-\sum_{k=1}^{o} q_{j k}^{*}\right] \times\left[\gamma_{j}-\gamma_{j}^{*}\right] \\
+\sum_{k=1}^{o}\left[\sum_{j=1}^{n} q_{j k}^{*}-d_{k}\left(\rho_{3}^{*}\right)\right] \times\left[\rho_{3 k}-\rho_{3 k}^{*}\right] \geq 0, \quad \forall\left(Q^{1}, Q^{2}, \gamma, \rho_{3}\right) \in R_{+}^{m n+n o+n+o} .
\end{gathered}
$$

The variables in the variational inequality problem (9) are: the product shipments from the manufacturers to the retailers, $Q^{1}$ (from which one can then recover also the production outputs through (1)); the product flows from the retailers to the demand markets, $Q^{2}$; the prices associated with handling the product by the retailers, $\gamma$, and the demand market prices $\rho_{3}$. The solution of the variational inequality problem (9), which coincides with the 
equilibrium product flow and price pattern according to Definition 1, in turn, is denoted by $\left(Q^{1^{*}}, Q^{2^{*}}, \gamma^{*}, \rho_{3}^{*}\right)$

We will utilize the following corollary, due to Nagurney, Dong, and Zhang (2002), to derive variational inequality formulations alternative to (9) that we will use in Section 4 to construct the supernetwork equivalence of the supply chain network equilibrium model with a properly configured traffic network equilibrium model with elastic demand that will be reviewed in Section 3.

\section{Corollary 1 (Nagurney, Dong, and Zhang (2002))}

The market for the product clears for each retailer at the supply chain network equilibrium.

With this corollary, it is clear that the structure of the supply chain network in equilibrium is as depicted in Figure 1 since conservation of flow equations (5) hold as equalities for all retailer nodes. Moreover, according to (1), the quantities produced by each manufacturer must be equal to the sum of the shipments from the manufacturer to the retailers. The equilibrium product shipments between the manufacturers and the retailers are given by the components of the vector $Q^{1^{*}}$ and correspond to the flows on the links connecting the top tier of nodes with the middle tier of nodes in Figure 1. The equilibrium product shipments between the retailers and the demand markets are given by the components of the vector $Q^{2^{*}}$ and correspond to the flows on the links connecting the middle tier of nodes with the bottom tier of nodes in Figure 1.

The equilibrium prices associated with the demand markets, in turn, are associated with the bottom tier nodes in Figure 1 and are given by the components of the vector $\rho_{3}^{*}$. The equilibrium prices associated with the middle tier of nodes in Figure 1 corresponding to the retailers are given by the $\rho_{2 j}^{*}$ s and $\gamma^{*}$. Finally, the equilibrium prices associated with the manufacturers at the top tier of nodes in Figure 1 are given by the $\rho_{1 i j}^{*} \mathrm{~s}$ for all $i, j$.

As noted in Nagurney, Dong, and Zhang (2002), the top tier prices can be recovered once variational inequality (9) is solved as follows. From (3) it follows that if $q_{i j}^{*}>0$ then $\rho_{1 i j}^{*}=\frac{\partial f_{i}\left(Q^{1 *}\right)}{\partial q_{i j}}+\frac{\partial c_{i j}\left(q_{i j}^{*}\right)}{\partial q_{i j}}$ or, equivalently, from (6) that $\rho_{1 i j}^{*}=\gamma_{j}^{*}-\frac{\partial c_{j}\left(Q^{1 *}\right)}{\partial q_{i j}}$. The middle tier prices, in turn, can be recovered from either (6) or (7) by setting $\rho_{2 j}^{*}=\gamma_{j}^{*}$ for a retailer $j$ 
such that $q_{j k}^{*}>0$ or $\rho_{2 j}^{*}=\rho_{3 k}^{*}-c_{j k}\left(Q^{2 *}\right)$.

Indeed, such a pricing mechanism is crucial and guarantees that the sum of (3), (6), and the variational inequality formulation of (7) and (8) for all demand markets, which yields variational inequality (9), corresponds to an equilibrium in the sense of Definition 1.

As a consequence of Corollary 1, we know that, at equilibrium, the flow of product out of each middle tier retailer node is equal to the flow of product in. Since we are interested in the determination of the equilibrium flows and prices, we can, hence, convert constraint (5) to:

$$
\sum_{k=1}^{o} q_{j k}=\sum_{i=1}^{m} q_{i j}, \quad j=1, \ldots, n
$$

and define the feasible set as $\mathcal{K} \equiv\left\{\left(Q^{1}, Q^{1}, \rho_{3}\right) \in R_{+}^{m n+n o+o}\right.$ such that $(5)$ holds $\}$.

In addition, for notational convenience, and subsequent use in establishing the equivalence in Section 4, we let

$$
d_{k} \equiv \sum_{j=1}^{n} q_{j k}, \quad k=1, \ldots, n
$$

and

$$
s_{j} \equiv \sum_{k=1}^{o} q_{j k}, \quad j=1, \ldots, n
$$

The following result is then immediate:

\section{Corollary 2}

A solution $\left(Q^{1 *}, Q^{2 *}, \rho_{3}^{*}\right) \in \mathcal{K}$ to the variational inequality problem:

$$
\begin{gathered}
\sum_{i=1}^{m} \sum_{j=1}^{n}\left[\frac{\partial f_{i}\left(Q^{1 *}\right)}{\partial q_{i j}}+\frac{\partial c_{i j}\left(q_{i j}^{*}\right)}{\partial q_{i j}}+\frac{\partial c_{j}\left(Q^{1 *}\right)}{\partial q_{i j}}\right] \times\left[q_{i j}-q_{i j}^{*}\right] \\
+\sum_{j=1}^{n} \sum_{k=1}^{o}\left[c_{j k}\left(Q^{2 *}\right)-\rho_{3 k}^{*}\right] \times\left[q_{j k}-q_{j k}^{*}\right]+\sum_{k=1}^{o}\left[\sum_{j=1}^{n} q_{j k}^{*}-d_{k}\left(\rho_{3}^{*}\right)\right] \times\left[\rho_{3 k}-\rho_{3 k}^{*}\right] \geq 0, \\
\forall\left(Q^{1}, Q^{2}, \rho_{3}\right) \in \mathcal{K} ;
\end{gathered}
$$

equivalently, a solution $\left(q^{*}, Q^{1 *}, s^{*}, Q^{2 *}, d^{*}, \rho_{3}^{*}\right) \in \mathcal{K}^{2}$ to:

$$
\sum_{i=1}^{m}\left[\frac{\partial f_{i}\left(q^{*}\right)}{\partial q_{i}}\right] \times\left[q_{i}-q_{i}^{*}\right]+\sum_{i=1}^{m} \sum_{j=1}^{n}\left[\frac{\partial c_{i j}\left(q_{i j}^{*}\right)}{\partial q_{i j}}\right] \times\left[q_{i j}-q_{i j}^{*}\right]+\sum_{j=1}^{n}\left[\frac{\partial c_{j}\left(s^{*}\right)}{\partial s_{j}}\right] \times\left[s_{j}-s_{j}^{*}\right]
$$




$$
\begin{gathered}
+\sum_{j=1}^{n} \sum_{k=1}^{o}\left[c_{j k}\left(Q^{2 *}\right)\right] \times\left[q_{j k}-q_{j k}^{*}\right]-\sum_{k=1}^{o} \rho_{3 k}^{*} \times\left[d_{k}-d_{k}^{*}\right] \\
+\sum_{k=1}^{o}\left[d_{k}^{*}-d_{k}\left(\rho_{3}^{*}\right)\right] \times\left[\rho_{3 k}-\rho_{3 k}^{*}\right] \geq 0, \quad \forall\left(q, Q^{1}, s, Q^{2}, d, \rho_{3}\right) \in \mathcal{K}^{2},
\end{gathered}
$$

where $\mathcal{K}^{2} \equiv\left\{\left(q, Q^{1}, s, Q^{2}, d, \rho_{3}\right) \mid\left(q, Q^{1}, s, Q^{2}, s, \rho_{3}\right) \in R_{+}^{m+m n+n+n o+2 o}\right.$ and $(1),(10)-(12)$, hold $\}$ also satisfies variational inequality (9).

Proof: We establish the result by contradiction. In particular, we show that if (9) does not hold, then (13a) does not hold. We assume, thus, that for some $\left(Q^{1}, Q^{2}, \rho_{3}\right) \in \mathcal{K}$ with $\gamma \in R_{+}^{n}$ that the left-hand side of (9) is less than or equal to zero, which implies that:

$$
\begin{gathered}
\sum_{i=1}^{m} \sum_{j=1}^{n}\left[\frac{\partial f_{i}\left(Q^{1 *}\right)}{\partial q_{i j}}+\frac{\partial c_{i j}\left(q_{i j}^{*}\right)}{\partial q_{i j}}+\frac{\partial c_{j}\left(Q^{1 *}\right)}{\partial q_{i j}}\right] \times\left[q_{i j}-q_{i j}^{*}\right] \\
+\sum_{j=1}^{n} \sum_{k=1}^{o}\left[c_{j k}\left(Q^{2 *}\right)-\rho_{3 k}^{*}\right] \times\left[q_{j k}-q_{j k}^{*}\right]+\sum_{k=1}^{o}\left[\sum_{j=1}^{n} q_{j k}^{*}-d_{k}\left(\rho_{3}^{*}\right)\right] \times\left[\rho_{3 k}-\rho_{3 k}^{*}\right] \\
\leq \sum_{i=1}^{m} \sum_{j=1}^{n} \gamma_{j}^{*}\left[q_{i j}-q_{i j}^{*}\right] \\
-\sum_{j=1}^{n} \sum_{k=1}^{o} \gamma_{j}^{*}\left[q_{j k}-q_{j k}^{*}\right]-\sum_{j=1}^{n}\left[\sum_{i=1}^{m} q_{i j}^{*}-\sum_{k=1}^{o} q_{j k}^{*}\right] \times\left[\gamma_{j}-\gamma_{j}^{*}\right] .
\end{gathered}
$$

But, after algebraic simplification and the use of Corollary (1), we conclude that the righthand side of (14) is equal to zero. Hence, (13a) cannot hold, and the conclusion follows.

Variational inequality (13b) is equivalent to variational inequality (13a) through simple algebraic relationships and the use of (1) and the definitions (11) and (12).

We will utilize variational inequality (13b) in Section 4 when we construct the isomorphic traffic network equilibrium of the supply chain network equilibrium through an appropriately identified supernetwork configuration. 


\section{The Traffic Network Equilibrium Model with Elastic Demand}

In this Section, we review a traffic network equilibrium model with elastic demands in which it is assumed that the demand functions associated with the origin/destination $(\mathrm{O} / \mathrm{D})$ pairs are given. We present the single modal version of the model of Dafermos and Nagurney (1984). For a traffic network equilibrium model in the case of known travel disutility (rather than the demand) functions, see Dafermos (1982).

We consider a network $G$ with the set of links $L$ consisting of $K$ elements, the set of paths $P$ consisting of $Q$ elements, and $W$ denoting the set of $\mathrm{O} / \mathrm{D}$ pairs with $Z$ elements. Let $P_{w}$ denote the set of paths joining $\mathrm{O} / \mathrm{D}$ pair $w$. Links are denoted by $a, b$, etc; paths by $p, q$, etc., and $\mathrm{O} / \mathrm{D}$ pairs by $w, \omega$, etc.

The flow on a path $p$ is denoted by $x_{p}$ and the flow on a link $a$ by $f_{a}$. The user travel cost on a path $p$ is denoted by $C_{p}$ and the user travel cost on a link $a$ by $c_{a}$. The travel demand associated with traveling between O/D pair $w$ is denoted by $d_{w}$ and the travel disutility by $\lambda_{w}$.

We assume that the flows on links are related to the flows on the paths by the conservation of flow equations:

$$
f_{a}=\sum_{p \in P} x_{p} \delta_{a p}, \quad \forall a \in L,
$$

where $\delta_{a p}=1$ if link $a$ is contained in path $p$, and $\delta_{a p}=0$, otherwise.

The user costs on paths are related to user costs on links as follows:

$$
C_{p}=\sum_{a \in L} c_{a} \delta_{a p}, \quad \forall p \in P,
$$

that is, the user cost on a path is equal to the sum of user costs on links that comprise the path.

Here we consider the general situation where the cost on a link may depend upon the entire vector of link flows, denoted by $f$, so that

$$
c_{a}=c_{a}(f), \quad \forall a \in L .
$$


Also, we assume, as given, travel demand functions, such that

$$
d_{w}=d_{w}(\lambda), \quad \forall w \in W,
$$

where $\lambda$ is the vector of travel disutilities with the travel disutility associated with $\mathrm{O} / \mathrm{D}$ pair being denoted by $\lambda_{w}$.

As given in Dafermos and Nagurney (1984); see also Aashtiani and Magnanti (1981), Fisk and Boyce (1982), Nagurney and Zhang (1996), and Nagurney (1999), a travel path flow and disutility pattern $\left(x^{*}, \lambda^{*}\right) \in R_{+}^{Q Z}$ is said to be an equilibrium, if, once established, no user has any incentive to alter his travel choices. The state is characterized by the following equilibrium conditions which must hold for every O/D pair $w \in W$ and every path $p \in P_{w}$ :

$$
C_{p}\left(x^{*}\right)-\lambda_{w}^{*}\left\{\begin{array}{lll}
=0, & \text { if } & x_{p}^{*}>0 \\
\geq 0, & \text { if } & x_{p}^{*}=0
\end{array}\right.
$$

and

$$
\sum_{p \in P_{w}} x_{p}^{*}\left\{\begin{array}{lll}
=d_{w}\left(\lambda^{*}\right), & \text { if } \quad \lambda_{w}^{*}>0 \\
\geq d_{w}\left(\lambda^{*}\right), & \text { if } \quad \lambda_{w}^{*}=0 .
\end{array}\right.
$$

Condition (19) states that all utilized paths connecting an O/D pair have equal and minimal travel costs and these costs are equal to the travel disutility associated with traveling between that O/D pair. Condition (20) states that the market clears for each O/D pair under a positive price or travel disutility. As described in Dafermos and Nagurney (1984) the traffic network equilibrium conditions (18) and (19) can be formulated as the variational inequality: determine $\left(x^{*}, \lambda^{*}\right) \in R_{+}^{Q Z}$ such that

$\sum_{w \in W} \sum_{p \in P_{w}}\left[C_{p}\left(x^{*}\right)-\lambda_{w}^{*}\right] \times\left[x_{p}-x_{p}^{*}\right]+\sum_{w \in W} \sum_{p \in P_{w}}\left[x_{p}^{*}-d_{w}\left(\lambda^{*}\right)\right] \times\left[\lambda_{w}-\lambda_{w}^{*}\right] \geq 0, \quad \forall(x, \lambda) \in R_{+}^{Q Z}$.

Note that variational inequality (21) is in path flows. Now we also provide the equivalent variational inequality but in link flows, also due to Dafermos and Nagurney (1984). For additional background, see the book by Nagurney (1999).

\section{Theorem 2}

A travel link flow pattern and associated travel demand and disutility pattern is a traffic network equilibrium if and only if it satisfies the variational inequality problem: determine 
$\left(f^{*}, d^{*}, \lambda^{*}\right) \in \mathcal{K}^{3}$ satisfying

$\sum_{a \in L} c_{a}\left(f^{*}\right) \times\left(f_{a}-f_{a}^{*}\right)-\sum_{w} \lambda_{w}^{*} \times\left(d_{w}-d_{w}^{*}\right)+\sum_{w \in W}\left[d_{w}^{*}-d_{w}\left(\lambda^{*}\right)\right] \times\left[\lambda_{w}-\lambda_{w}^{*}\right] \geq 0, \quad \forall(f, d, \lambda) \in \mathcal{K}^{3}$,

where $\mathcal{K}^{3} \equiv\left\{(f, d, \lambda) \in R_{+}^{K+2 Z} \mid\right.$ there exists an $(x)$ satisfying $(15)$ and $\left.d_{w}=\sum_{p \in P_{w}} x_{p}, \forall w\right\}$.

In the next Section, we will construct the traffic network configuration (through a supernetwork construction) of the supply chain network model in Section 2 and we will show that the link flow variational inequality (22) for the constructed supernetwork coincides with variational inequality (13b). 


\section{Supernetwork Equivalence of the Supply Chain Network Equilibrium Model}

It is now well-established that a plethora of equilibrium models arising in different disciplines can be cast into the form of a traffic network equilibrium problem with either fixed or elastic travel demands. For a variety of such applications ranging from Walrasian price equilibrium problems to spatial price equilibrium problems, see the book by Nagurney (1999) and the references therein. In this Section, we demonstrate, through a supernetwork construction of the supply chain network equilibrium model described in Section 2, that supply chain network equilibrium problems can also be cast into a traffic network equilibrium problem with elastic demands and with a particular configuration. This identification then allows us to transfer the relevant theory and algorithms developed to-date for the latter problem for the study and solution of the former. We then utilize this identification, in Section 5, where we solve supply chain network equilibrium examples from the literature via an algorithm developed for traffic network equilibrium problems with elastic demands.

In particular, we cast the supply chain network equilibrium problem into supernetwork form, which then reveals the configuration of the associated isomorphic traffic network equilibrium problem. By constructing the associated supernetwork, which is an abstract network (see also Nagurney and Dong (2002)), the linkages to traffic network equilibrium become apparent through the identification of the origin/destination pairs, the paths connecting the origin/destination pairs, the costs on the links of the supernetwork, and the origin/destination pair demand functions and travel disutilities. We note that isomorphic traffic networks have been identified in the case of spatial price equilibrium problems, single and multimodal ones, respectively, by Dafermos and Nagurney (1985) and Dafermos (1986).

We now show that the supply chain network equilibrium model of Section 2 is isomorphic to a particular configuration of the traffic network equilibrium model described in Section 3, which is a supernetwork and which is constructed, cf. Figure 2, as follows. 


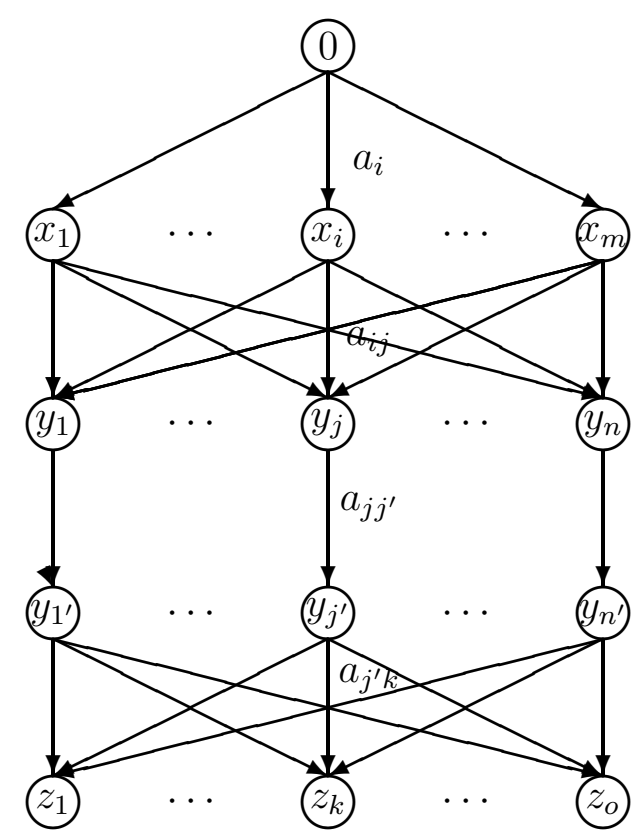

Figure 2: The $G_{S}$ Supernetwork Representation of Supply Chain Network Equilibrium 
Consider a supply chain as discussed in Section 2 with given manufacturers: $i=1, \ldots, m$; retailers: $j=1, \ldots, n$, and demand markets: $k=1, \ldots, o$. We construct the supernetwork $G_{S}$, shown in Figure 2, of the isomorphic traffic network equilibrium model as follows: $G_{S}$ consists of the single origin node 0 , and $o$ destination nodes at the bottom tier of nodes in Figure 2, denoted, respectively, by: $z_{1}, \ldots, z_{o}$. There are $o \mathrm{O} / \mathrm{D}$ pairs in $G_{S}$ denoted, respectively, by $w_{1}=\left(0, z_{1}\right), \ldots, w_{k}=\left(0, z_{k}\right), \ldots, w_{o}=\left(0, z_{o}\right)$. There are $m$ links emanating from node 0 with each such single link joining node 0 and terminating in second tiered node $x_{i} ; i=1, \ldots, m$. From each such node $x_{i}$, in turn, there are $n$ links emanating with a given such link ending in third tiered node $y_{j}$, where $j=1, \ldots, n$. Each node $y_{j}$, in turn, is connected with node $y_{j}^{\prime}$ by a single link. Finally, from each fourth-tiered node there are $o$ links emanating to the bottom tiered nodes. There are, hence, $1+m+2 n+o$ nodes in the supernetwork in Figure 2, $K=m+m n+n+n o$ links, $Z=o \mathrm{O} / \mathrm{D}$ pairs, and $Q=m o$ paths.

We now turn our attention to the definition of the links in the supernetwork in Figure 2 and the associated flows. Let $a_{i}$ denote the link from node 0 to node $x_{i}$ with associated link flow $f_{a_{i}}$, for $i=1, \ldots, m$. Let $a_{i j}$ denote the link from node $x_{i}$ to node $y_{j}$ with associated link flow $f_{a_{i j}}$ for $i=1, \ldots, m$ and $j=1, \ldots, n$. Also, let $a_{j j^{\prime}}$ denote the link connecting node $y_{j}$ with node $y_{j^{\prime}}$ with associated link flow $f_{a_{j j^{\prime}}}$ for $j ; j^{\prime}=1, \ldots, n$. Finally, let $a_{j^{\prime} k}$ denote the link joining node $y_{j^{\prime}}$ with node $z_{k}$ for $j^{\prime}=1^{\prime}, \ldots, n^{\prime}$ and $k=1, \ldots, o$ and with associated link flow $f_{a_{j^{\prime}} k}$. We group the link flows into the vectors, respectively, as follows: we group the $\left\{f_{a_{i}}\right\}$ into the vector $f^{1}$; the $\left\{f_{a_{i j}}\right\}$ into the vector $f^{2}$; the $\left\{f_{a_{j j^{\prime}}}\right\}$ into the vector $f^{3}$, and the $\left\{f_{a_{j^{\prime} k}}\right\}$ into the vector $f^{4}$.

A typical path, hence, joining origin node 0 with destination node $z_{k}$, consists of four links. We, thus, note a typical path by $p_{i j j^{\prime} k}$ which means that this path consists of links: $a_{i}, a_{i j}, a_{j j^{\prime}}$, and $a_{j^{\prime} k}$ with the associated flow on the path equal to $x_{p_{i j j^{\prime} k}}$. Also, we let $d_{w_{k}}$ denote the demand associated with $\mathrm{O} / \mathrm{D}$ pair $w_{k}$ and $\lambda_{w_{k}}$ the travel disutility for $w_{k}$.

Note that the satisfaction of the conservation of flow equations (15) means that:

$$
\begin{gathered}
f_{a_{i}}=\sum_{j j^{\prime} k} x_{p_{i j j^{\prime} k}}, \quad i=1, \ldots, m, \\
f_{a_{i j}}=\sum_{j^{\prime} k} x_{p_{i j j^{\prime} k}}, \quad i=1, \ldots, m ; j=1, \ldots, n,
\end{gathered}
$$




$$
\begin{aligned}
& f_{a_{j j^{\prime}}}=\sum_{i k} x_{p_{i j j^{\prime} k}}, \quad j=1, \ldots, n ; j^{\prime}=1, \ldots, n, \\
& f_{a_{j^{\prime} k}}=\sum_{i j} x_{p_{i j j^{\prime} k},}, \quad j^{\prime}=1, \ldots, n ; k=1, \ldots, o .
\end{aligned}
$$

Also, we have that

$$
d_{w_{k}}=\sum_{i j j^{\prime}} x_{i j j^{\prime} k}, \quad k=1, \ldots, o
$$

A path flow pattern induces a feasible link flow pattern if all path flows are nonnegative and (23)-(27) are satisfied.

Suppose now that we are given a feasible product shipment pattern for the supply chain model, $\left(q, Q^{1}, s, Q^{2}, d\right) \in \mathcal{K}^{2}$, that is, $Q^{1}$ and $Q^{2}$ consist of nonnegative product shipments and (1) and (10) - -(12) are satisfied. We may construct a feasible link flow pattern on the network $G_{s}$ as follows: the link flows and travel demands are defined as:

$$
\begin{gathered}
q_{i} \equiv f_{a_{i}}, \quad i=1, \ldots, m, \\
q_{i j} \equiv f_{a_{i j}}, \quad i=1, \ldots, m ; j=1, \ldots, n, \\
s_{j} \equiv f_{a_{j j^{\prime}}}, \quad j=1, \ldots, n ; j^{\prime}=1, \ldots, n^{\prime}, \\
q_{j k}=f_{a_{j^{\prime} k}}, \quad j^{\prime}=1^{\prime}, \ldots, n^{\prime} ; k=1, \ldots, o, \\
d_{k}=\sum_{j=1}^{n} q_{j k}, \quad k=1, \ldots, o .
\end{gathered}
$$

Note that if $\left(q, Q^{1}, s, Q^{2}, d\right)$ is feasible then the link flow pattern constructed according to $(28)-(32)$ is also feasible and the corresponding path flow pattern that induces such a link flow (and demand) pattern is, hence, also feasible.

\section{Remark}

It is important to note that there is no explicit path flow concept in the supply chain network model of Section 2. However, given the above relationships and identifications in the link flow and demand patterns, we will be able to obtain path flows and an associated new interpretation of the supply chain network equilibrium conditions, as we will shortly show. 
We now assign travel costs on the links of the network $G_{S}$ as follows: with each link $a_{i}$ we assign a travel cost $c_{a_{i}}$ defined by

$$
c_{a_{i}} \equiv \frac{\partial f_{i}}{\partial q_{i}}, \quad i=1, \ldots, m,
$$

with each link $a_{i j}$ we assign a travel cost $c_{a_{i j}}$ defined by:

$$
c_{a_{i j}} \equiv \frac{\partial c_{i j}}{\partial q_{i j}}, \quad i=1, \ldots, m ; j=1, \ldots, n,
$$

with each link $j j^{\prime}$ we assign a travel cost defined by

$$
c_{a_{j j^{\prime}}} \equiv \frac{\partial c_{j}}{\partial s_{j}}, \quad j=1, \ldots, n ; j^{\prime}=1, \ldots, n .
$$

Finally, for each link $a_{j^{\prime} k}$ we assign a travel cost defined by

$$
c_{a_{j^{\prime} k}} \equiv c_{j k}, \quad j^{\prime}=1, \ldots, n^{\prime} ; k=1, \ldots, o .
$$

Then a traveler traveling on path $p_{i j j^{\prime} k}$, for $i=1, \ldots, m ; j=1, \ldots, n ; j^{\prime}=1^{\prime}, \ldots, n^{\prime}$; $k=1, \ldots, o$, on network $G_{S}$ in Figure 2 incurs a travel cost $C_{p_{i j j^{\prime} k}}$ given by

$$
C_{p_{i j j^{\prime} k}}=c_{a_{i}}+c_{a_{i j}}+c_{a_{j j^{\prime}}}+c_{a_{j^{\prime} k}}=\frac{\partial f_{i}}{\partial q_{i}}+\frac{\partial c_{i j}}{\partial q_{i j}}+\frac{\partial c_{j}}{\partial s_{j}}+c_{j k} .
$$

Also, we assign the travel demands associated with the O/D pairs as follows:

$$
d_{w_{k}} \equiv d_{k}, \quad k=1, \ldots, o
$$

and the travel disutilities:

$$
\lambda_{w_{k}} \equiv \rho_{3 k}, \quad k=1, \ldots, o .
$$

Consequently, the equilibrium conditions (19) and (20) for the traffic network equilibrium model on the network $G_{S}$ state that for every O/D pair $w_{k}$ and every path connecting the O/D pair $w_{k}$ :

$$
C_{p_{i j j^{\prime} k}}-\lambda_{w_{k}}^{*}=\frac{\partial f_{i}}{\partial q_{i}}+\frac{\partial c_{i j}}{\partial q_{i j}}+\frac{\partial c_{j}}{\partial q_{j}}+c_{j k}-\lambda_{w_{k}}^{*}\left\{\begin{array}{lll}
=0, & \text { if } & x_{p_{i j j^{\prime} k}}^{*}>0 \\
\geq 0, & \text { if } & x_{p_{i j j^{\prime} k}}^{*}=0
\end{array}\right.
$$


and

$$
\sum_{p \in P_{w_{k}}} x_{p_{i j j^{\prime} k}}^{*}\left\{\begin{array}{lll}
=d_{w_{k}}\left(\lambda^{*}\right), & \text { if } & \lambda_{w_{k}}^{*}>0 \\
\geq d_{w_{k}}\left(\lambda^{*}\right), & \text { if } & \lambda_{w_{k}}^{*}=0 .
\end{array}\right.
$$

We now state the variational inequality formulation of the equilibrium conditions (40) and (41) in link form as in (22), which will make apparent the equivalence with variational inequalities (13a) and (13b) for the supply chain network equilibrium. Indeed, according to Theorem 2, we have that a link flow, travel demand, and travel disutility pattern $\left(f^{*}, d^{*}, \lambda^{*}\right) \in$ $\mathcal{K}^{3}$ is an equilibrium (according to (40) and (41)), if and only if it satisfies:

$$
\begin{gathered}
\sum_{i=1}^{m} c_{a_{i}}\left(f^{1 *}\right) \times\left(f_{a_{i}}-f_{a_{i}}^{*}\right)+\sum_{i=1}^{m} \sum_{j=1}^{n} c_{a_{i j}}\left(f_{a_{i j}}\right) \times\left(f_{a_{i j}}-f_{a_{i j}}^{*}\right) \\
+\sum_{j=1}^{n} c_{a_{j j^{\prime}}}\left(f^{3 *}\right) \times\left(f_{a_{j^{\prime}}}-f_{a_{j j^{\prime}}}^{*}\right)+\sum_{j^{\prime}=1}^{n^{\prime}} \sum_{k=1}^{n} c_{a_{j^{\prime} k}}\left(f^{4 *}\right) \times\left(f_{a_{j^{\prime} k}}-f_{a_{j^{\prime} k}}^{*}\right) \\
-\sum_{k=1}^{o} \lambda_{w_{k}}^{*} \times\left(d_{w_{k}}-d_{w_{k}}^{*}\right)+\sum_{k=1}^{o}\left[d_{w_{k}}^{*}-d_{w_{k}}\left(\lambda^{*}\right)\right] \times\left[\lambda_{w_{k}}-\lambda_{w_{k}}^{*}\right] \geq 0, \quad \forall(f, d, \lambda) \in \mathcal{K}^{3},
\end{gathered}
$$

which, through expressions (28) - (32), (33) - (36), and (38) - (39) yields:

$$
\begin{gathered}
\sum_{i=1}^{m}\left[\frac{\partial f_{i}\left(q^{*}\right)}{\partial q_{i}}\right] \times\left[q_{i}-q_{i}^{*}\right]+\sum_{i=1}^{m} \sum_{j=1}^{n}\left[\frac{\partial c_{i j}\left(q_{i j}^{*}\right)}{\partial q_{i j}}\right] \times\left[q_{i j}-q_{i j}^{*}\right] \\
\left.+\sum_{j=1}^{n}\left[\frac{\partial c_{j}\left(s^{*}\right)}{\partial s_{j}}\right] \times\left[s_{j}-s_{j}^{*}\right]+\sum_{j=1}^{n} \sum_{k=1}^{o} c_{j k}\left(Q^{2 *}\right)\right] \times\left[q_{j k}-q_{j k}^{*}\right] \\
-\sum_{k=1}^{o} \rho_{3 k}^{*} \times\left[d_{k}-d_{k}^{*}\right]+\sum_{k=1}^{o}\left[d_{k}^{*}-d_{k}\left(\rho_{3}^{*}\right)\right] \times\left[\rho_{3 k}-\rho_{3 k}^{*}\right] \geq 0 \\
\forall\left(q, Q^{1}, s, Q^{2}, d, \rho_{3}\right) \in \mathcal{K}^{2} .
\end{gathered}
$$

But variational inequality (43) is precisely variational inequality (13b) governing the supply chain network equilibrium.

Hence, we have the following result: 


\section{Theorem 3}

A solution $\left(q^{*}, Q^{1^{*}}, s^{*}, Q^{2^{*}}, d^{*}, \rho_{3}^{*}\right) \in \mathcal{K}^{2}$ of the variational inequality (13b) governing a supply chain network equilibrium coincides with the (via (28) - (32) and (38) - (39)) feasible link flow, travel demand, and travel disutility pattern for the supernetwork $G_{s}$ constructed above and satisfies variational inequality (22). Hence, it is a traffic network equilibrium according to Theorem 2.

Observe that equilibrium conditions (40) and (41) provide us with an entirely new interpretation of the supply chain network equilibrium conditions according to Definition 1. Indeed, (40) coincides with the well-known Wardrop (1952) conditions associated with traffic network equilibria and user-optimization (see also Dafermos and Sparrow (1969)). Hence, we now have an entirely new interpretation of supply chain network equilibrium which states that all utilized paths in a supply chain supernetwork associated with a demand market will have equal and minimal costs. This further suggests a type of efficiency principle regarding supply chain designs. Moreover, the flow on a path of the supernetwork representation of the supply chain network corresponds to the flow of product along a path which consists of such links as production links $a_{i} ; i=1, \ldots, m$; transportation/transaction links between manufacturers and retailers: $a_{i j} ; i=1, \ldots, m ; j=1, \ldots, n$; handling links associated with the retailers: $a_{j j^{\prime}} ; j=1, \ldots, n ; j^{\prime}=1^{\prime}, \ldots, n^{\prime}$ and, finally, transportation/transaction links between retailers and the consumers at the demand markets: $a_{j^{\prime} k} ; j^{\prime}=1^{\prime}, \ldots, n^{\prime} ; j=1, \ldots, o$.

Note that using an analogous supernetwork construction to the one detailed here we can now construct traffic network equilibrium representations (and formulations) of additional supply chain network problems as cited in the Introduction of this paper. We note that Zhang, Dong, and Nagurney (2003) presented a supply chain network equilibrium model which recognized the importance of Wardrop's principles from traffic networks but considered a chain formulation, rather than a path formulation. Moreover, they reported no numerical results.

In Section 5, we show how Theorem 3 can be exploited to compute supply chain network equilibria consisting of product shipments and demand market prices using an algorithm developed for the solution of traffic network equilibrium problems with elastic demands. 


\section{The Algorithm and Numerical Examples}

In this Section, we first recall an algorithm, the Euler method, which was proposed by Nagurney and Zhang (1996) for the solution of variational inequality problem (21) in path flows (or, equivalently, variational inequality (22) in link flows). It has also been applied (in different realizations) to solve traffic network equilibrium problems with fixed travel demands, with known travel disutility functions, spatial price equilibrium problems, as well as other network equilibrium problems. In addition to the above cited reference, we also refer the interested reader to the book by Nagurney (1999).

In particular, due to the simplicity of the feasible set (cf. (21)), which is simply the nonnegative orthant, the Euler method (see also Dupuis and Nagurney (1993)) here takes the form: at iteration $\tau$ compute the path flows $p \in P$ according to:

$$
x_{p}^{\tau+1}=\max \left\{0, x_{p}^{\tau}+\alpha_{\tau}\left(\lambda_{w}^{\tau}-C_{p}\left(x^{\tau}\right)\right)\right\},
$$

and the travel disutilities for all $\mathrm{O} / \mathrm{D}$ pairs $w \in W$ according to:

$$
\lambda_{w}^{\tau+1}=\max \left\{0, \lambda_{w}^{\tau}+\alpha_{\tau}\left(d_{w}\left(\lambda^{\tau}\right)-\sum_{p \in P_{w}} x_{p}^{\tau}\right)\right\},
$$

where $\left\{\alpha_{\tau}\right\}$ is a sequence of positive real numbers that satisfies: $\lim _{\tau \rightarrow \infty} \alpha_{\tau}=0$ and $\sum_{\tau=1}^{\infty} \alpha_{\tau}=\infty$. Such a sequence is required for convergence (cf. Nagurney and Zhang (1996)).

Note that formulae (44) and (45) yield closed form expressions for the computation of the path flows and travel disutilities at an iteration $\tau$.

We now apply the Euler method described above to compute the equilibrium path, link flow, and travel disutility pattern in three numerical examples that were solved via the modified projection method (cf. Korpelevich (1977)) in Nagurney, Dong, and Zhang (2002). The Euler method was implemented in FORTRAN and the computer system used was a Sun system located at the University of Massachusetts at Amherst. The convergence criterion utilized was that the absolute value of the path flows and travel disutilities between two successive iterations differed by no more than $10^{-4}$. The sequence $\left\{\alpha_{\tau}\right\}$ in the Euler method was set to: $\left\{1, \frac{1}{2}, \frac{1}{2}, \frac{1}{3}, \frac{1}{3}, \frac{1}{3}, \ldots\right\}$. 


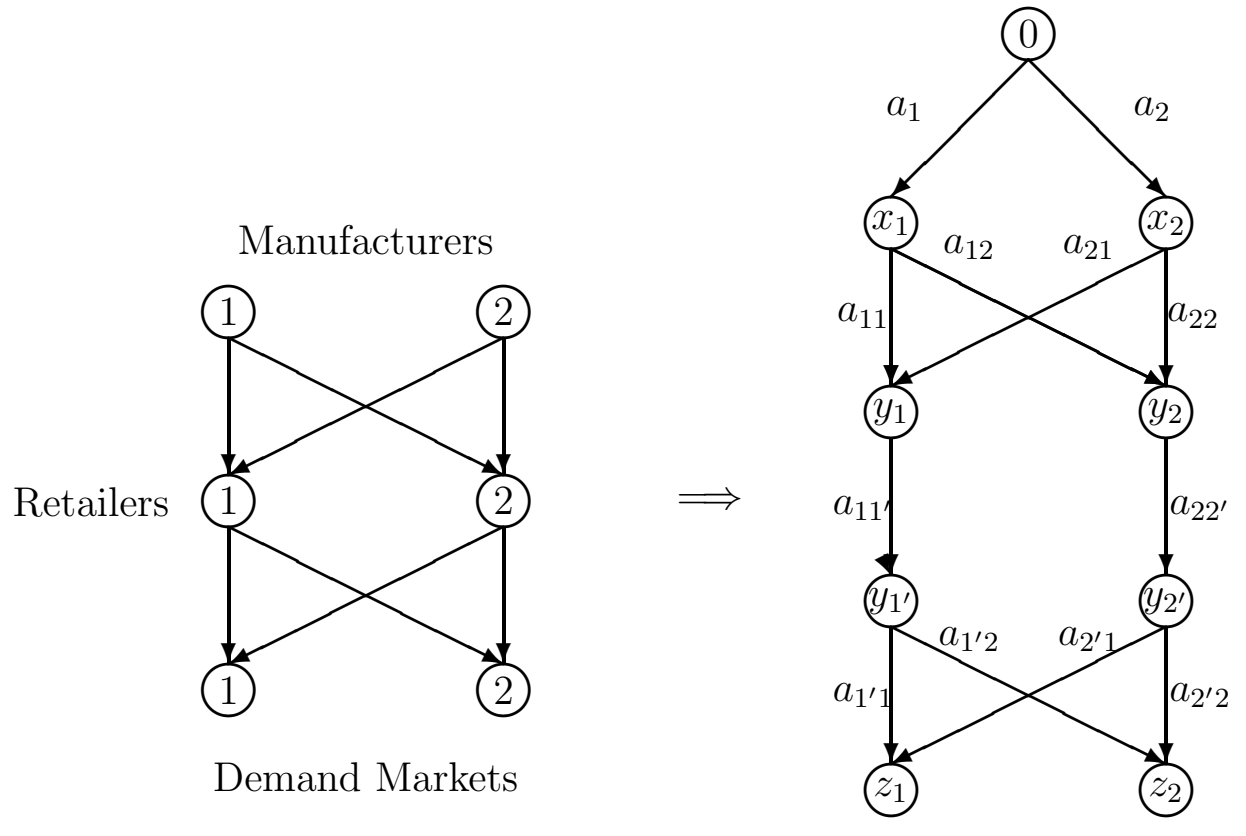

Figure 3: Supply Chain Network and Corresponding Supernetwork for Examples 1 and 2

\section{Example 1}

The first numerical example, depicted in Figure 3, consisted of two manufacturers, two retailers, and two demand markets. In Figure 3, we also provide the supernetwork representation and identify its nodes and links.

The data for this example were constructed for easy interpretation purposes and here they are recalled, for completeness and easy reference. The notation is presented for this and the subsequent examples in the form of the supply chain network equilibrium model in 
Section 2. The production cost functions for the manufacturers were given by:

$$
f_{1}(q)=2.5 q_{1}^{2}+q_{1} q_{2}+2 q_{1}, \quad f_{2}(q)=2.5 q_{2}^{2}+q_{1} q_{2}+2 q_{2} .
$$

The transaction cost functions faced by the manufacturers and associated with transacting with the retailers were given by:

$c_{11}\left(q_{11}\right)=.5 q_{11}^{2}+3.5 q_{11}, c_{12}\left(q_{12}\right)=.5 q_{12}^{2}+3.5 q_{12}, c_{21}\left(q_{21}\right)=.5 q_{21}^{2}+3.5 q_{21}, c_{22}\left(q_{22}\right)=.5 q_{22}^{2}+3.5 q_{22}$.

The handling costs of the retailers, in turn, were given by:

$$
c_{1}\left(Q^{1}\right)=.5\left(\sum_{i=1}^{2} q_{i 1}\right)^{2}, \quad c_{2}\left(Q^{1}\right)=.5\left(\sum_{i=1}^{2} q_{i 2}\right)^{2} .
$$

The demand functions at the demand markets were:

$$
d_{1}\left(\rho_{3}\right)=-2 \rho_{31}-1.5 \rho_{32}+1000, \quad d_{2}\left(\rho_{3}\right)=-2 \rho_{32}-1.5 \rho_{31}+1000,
$$

and the transaction costs between the retailers and the consumers at the demand markets were given by:

$$
c_{11}\left(Q^{2}\right)=q_{11}+5, \quad c_{12}\left(Q^{2}\right)=q_{12}+5, \quad c_{21}\left(Q^{2}\right)=q_{21}+5, \quad c_{22}\left(Q^{2}\right)=q_{22}+5 .
$$

We utilized the supernetwork representation of this example depicted in Figure 3 with the links enumerated as in Figure 3 in order to solve the problem via the Euler method. Notice that there are 9 nodes and 12 links in the supernetwork in Figure 3. Using the procedure outlined in Section 4, we defined O/D pair $w_{1}=\left(0, z_{1}\right)$ and $\mathrm{O} / \mathrm{D}$ pair $w_{2}=\left(0, z_{2}\right)$ and associated the demand price functions with the travel disutility functions as in (39) and the user link travel cost functions as given in (33)-(36) (analogous constructions were done for the subsequent examples).

There were four paths in $P_{w_{1}}$ denoted by: $p_{1}, p_{2}, p_{3}$, and $p_{4}$, respectively, and also four paths in $P_{w_{2}}$ denoted by: $p_{5}, p_{6}, p_{7}$, and $p_{8}$, respectively, and comprised of the links as follows: 
for $\mathrm{O} / \mathrm{D}$ pair $w_{1}$ :

$$
\begin{array}{ll}
p_{1}=\left(a_{1}, a_{11}, a_{11^{\prime}}, a_{1^{\prime} 1}\right), & p_{2}=\left(a_{1}, a_{12}, a_{22^{\prime}}, a_{2^{\prime} 1}\right), \\
p_{3}=\left(a_{2}, a_{21}, a_{11^{\prime}}, a_{1^{\prime} 1}\right), & p_{4}=\left(a_{2}, a_{22}, a_{22^{\prime}}, a_{2^{\prime} 1}\right),
\end{array}
$$

and for $\mathrm{O} / \mathrm{D}$ pair $w_{2}$ :

$$
\begin{array}{ll}
p_{5}=\left(a_{1}, a_{11}, a_{11^{\prime}}, a_{1^{\prime} 2}\right), & p_{6}=\left(a_{1}, a_{12}, a_{22^{\prime}}, a_{2^{\prime} 2}\right), \\
p_{3}=\left(a_{2}, a_{21}, a_{11^{\prime}}, a_{1^{\prime} 2}\right), & p_{8}=\left(a_{2}, a_{22}, a_{22^{\prime}}, a_{2^{\prime} 2}\right) .
\end{array}
$$

The Euler method converged in 194 iterations and yielded the following equilibrium pattern:

$$
\begin{aligned}
& x_{p_{1}}^{*}=x_{p_{2}}^{*}=x_{p_{3}}^{*}=x_{p_{4}}^{*}=8.304, \\
& x_{p_{5}}^{*}=x_{p_{6}}^{*}=x_{p_{7}}^{*}=x_{p_{8}}^{*}=8.304,
\end{aligned}
$$

and with the equilibrium travel disutilities given by:

$$
\lambda_{w_{1}}^{*}=\lambda_{w_{2}}^{*}=276.224 .
$$

The corresponding equilibrium link flows were:

$$
\begin{gathered}
f_{a_{1}}^{*}=f_{a_{2}}^{*}=33.216, \quad f_{a_{11}}^{*}=f_{a_{12}}^{*}=f_{a_{21}}^{*}=f_{a_{22}}^{*}=16.608, \\
f_{a_{11^{\prime}}}^{*}=f_{a_{22^{\prime}}}^{*}=33.216, \quad f_{a_{1^{\prime} 1}}^{*}=f_{a_{1^{\prime} 2}}^{*}=f_{a_{2^{\prime} 1}}^{*}=f_{a_{2^{\prime} 2}}^{*}=16.608 .
\end{gathered}
$$

We now provide the translations of the above equilibrium flows into the supply chain product shipment and price notation using (28)-(32).

The product shipments between the two manufacturers and the two retailers were: $Q^{1^{*}}=$ $q_{11}^{*}=q_{12}^{*}=q_{21}^{*}=q_{22}^{*}=16.608$, the product shipments (consumption volumes) between the two retailers and the two demand markets were: $Q^{2 *}=q_{11}^{*}=q_{12}^{*}=q_{21}^{*}=q_{22}^{*}=16.608$, and the demand prices at the demand markets were: $\rho_{31}^{*}=\rho_{32}^{*}=276.224$.

It is easy to verify that the optimality/equilibrium conditions were satisfied with good accuracy.

Moreover, these values are precisely the same values obtained for the equilibrium product shipments and demand market prices for Example 1 via the modified projection method in Nagurney, Dong, and Zhang (2002). 


\section{Example 2}

We then modified Example 1 as follows: The production cost function for manufacturer 1 was now given by:

$$
f_{1}(q)=2.5 q_{1}^{2}+q_{1} q_{2}+12 q_{1},
$$

whereas the transaction costs for manufacturer 1 were now given by:

$$
c_{11}\left(q_{11}\right)=q_{11}^{2}+3.5 q_{11}, \quad c_{12}\left(q_{12}\right)=q_{12}^{2}+3.5 q_{12} .
$$

The remainder of the data was as in Example 1. Hence, both the production costs and the transaction costs increased for manufacturer 1 .

We next (as in the case of Example 1) constructed the supernetwork reformulation and applied the Euler method. Hence, since the number of manufacturers, retailers, and demand markets did not change the supernetwork representation for this example is as depicted in Figure 3.

The Euler method converged in 197 iterations and yielded the following equilibrium path flow and travel disutility pattern:

$$
\begin{gathered}
x_{p_{1}}^{*}=x_{p_{2}}^{*}=7.234, \quad x_{p_{3}}^{*}=x_{p_{4}}^{*}=8.635, \\
x_{p_{5}}^{*}=x_{p_{6}}^{*}=7.274, \quad x_{p_{7}}^{*}=x_{p_{8}}^{*}=8.595, \\
\lambda_{w_{1}}^{*}=\lambda_{w_{2}}^{*}=276.397 .
\end{gathered}
$$

The equilibrium link flows were:

$$
\begin{gathered}
f_{a_{1}}^{*}=29.014, \quad f_{a_{2}}^{*}=34.460, \quad f_{a_{11}}^{*}=14.507=f_{a_{12}}^{*}, \quad f_{a_{21}}^{*}=f_{a_{22}}^{*}=17.230, \\
f_{a_{11^{\prime}}}^{*}=f_{a_{22^{\prime}}}^{*}=31.737, \quad f_{a_{1^{\prime} 1}}^{*}=f_{a_{1^{\prime} 2}}^{*}=f_{a_{2^{\prime} 1}}^{*}=f_{a_{2^{\prime} 2}}^{*}=15.870 .
\end{gathered}
$$

We now, for easy reference, and comparison with the results for this example, but solved via the modified projection method in Nagurney, Dong, and Zhang (2002), provide the translations of the above results into the supply chain notation for equilibrium product shipments and demand market prices. 
The product shipments between the two manufacturers and the two retailers were now: $Q^{1^{*}}=q_{11}^{*}=q_{12}^{*}=14.507, \quad q_{21}^{*}=q_{22}^{*}=17.230$, the product shipments (consumption amounts) between the two retailers and the two demand markets were now: $Q^{2 *}=q_{11}^{*}=$ $q_{12}^{*}=q_{21}^{*}=q_{22}^{*}=15.870$, and the demand prices at the demand markets were: $\rho_{31}^{*}=\rho_{32}^{*}=$ 276.646 .

Hence, manufacturer 1 now produced less than it did in Example 1, whereas manufacturer 2 increased its production output. The demand price at the demand markets increased, with a decrease in the incurred demand.

The equilibrium product shipments and demand market prices computed via the Euler method were precisely equal to the correpsonding values obtained via the modified projection method for Example 2 by Nagurney, Dong, and Zhang (2002).

\section{Example 3}

The third supply chain network problem consisted of two manufacturers, three retailers, and two demand markets, as depicted in Figure 4. Its supernetwork representation is also given in Figure 4.

The data were constructed from Example 2, but we added data for the manufacturers' transaction costs associated with the third retailer; handling cost data for the third retailer, as well as the transaction cost data between the new retailer and the demand markets. Hence, the complete data for this example were given by:

The production cost functions for the manufacturers were given by:

$$
f_{1}(q)=2.5 q_{1}^{2}+q_{1} q_{2}+2 q_{1}, \quad f_{2}(q)=2.5 q_{2}^{2}+q_{1} q_{2}+12 q_{2} .
$$

The transaction cost functions faced by the two manufacturers and associated with transacting with the three retailers were given by:

$$
\begin{gathered}
c_{11}\left(q_{11}\right)=q_{11}^{2}+3.5 q_{11}, \quad c_{12}\left(q_{12}\right)=q_{12}^{2}+3.5 q_{12}, \quad c_{13}\left(q_{13}\right)=.5 q_{13}^{2}+5 q_{13}, \\
c_{21}\left(q_{21}\right)=.5 q_{21}^{2}+3.5 q_{21}, \quad c_{22}\left(q_{22}\right)=.5 q_{22}^{2}+3.5 q_{22}, \quad c_{23}\left(q_{23}\right)=.5 q_{23}^{2}+5 q_{23} .
\end{gathered}
$$




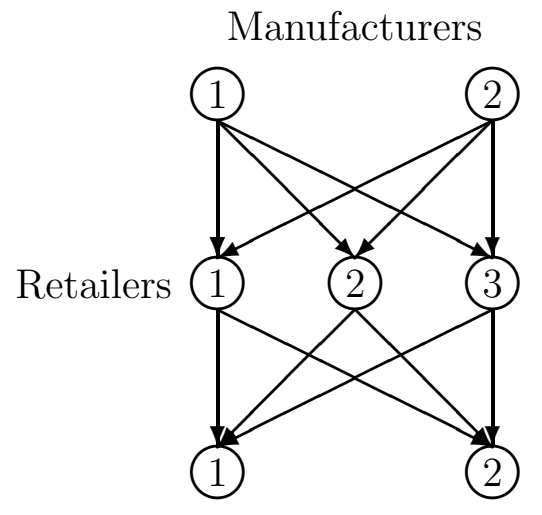

Demand Markets

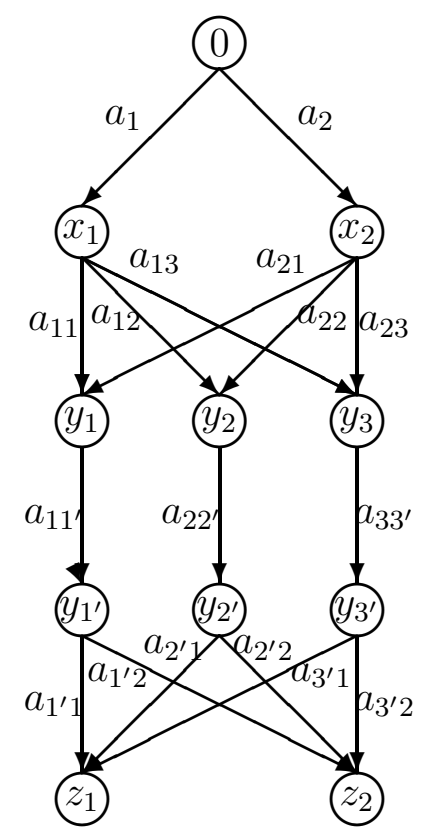

Figure 4: Supply Chain Network and Corresponding Supernetwork for Example 3 
The handling costs of the retailers, in turn, were given by:

$$
c_{1}\left(Q^{1}\right)=.5\left(\sum_{i=1}^{2} q_{i 1}\right)^{2}, \quad c_{2}\left(Q^{1}\right)=.5\left(\sum_{i=1}^{2} q_{i 2}\right)^{2}, \quad c_{3}\left(Q^{1}\right)=.5\left(\sum_{i=1}^{2} q_{i 3}\right)^{2} .
$$

The demand functions at the demand markets, again, were:

$$
d_{1}\left(\rho_{3}\right)=-2 \rho_{31}-1.5 \rho_{32}+1000, \quad d_{2}\left(\rho_{3}\right)=-2 \rho_{32}-1.5 \rho_{31}+1000,
$$

and the transaction costs between the retailers and the consumers at the demand markets were given by:

$$
\begin{array}{ll}
c_{11}\left(Q^{2}\right)=q_{11}+5, & c_{12}\left(Q^{2}\right)=q_{12}+5, \\
c_{21}\left(Q^{2}\right)=q_{21}+5, & c_{22}\left(Q^{2}\right)=q_{22}+5, \\
c_{31}\left(Q^{2}\right)=q_{31}+5, & c_{32}\left(Q^{2}\right)=q_{32}+5 .
\end{array}
$$

Note that in the supernetwork representation of this supply chain network problem, given in Figure 4, there are 11 nodes in the supernetwork and 17 links. There are two O/D pairs given by $w_{1}=\left(0, z_{1}\right)$ and $w_{2}=\left(1, z_{2}\right)$ with the nodes $z_{1}$ and $z_{2}$ corresponding to the bottom tiered nodes in the supernetwork in Figure 4.

There are now six paths connecting each O/D pair and given as follows: for $\mathrm{O} / \mathrm{D}$ pair $w_{1}$ :

$$
\begin{array}{lll}
p_{1}=\left(a_{1}, a_{11}, a_{11^{\prime}}, a_{1^{\prime} 1}\right), & p_{2}=\left(a_{1}, a_{12}, a_{22^{\prime}}, a_{2^{\prime} 1}\right), & p_{3}=\left(a_{1}, a_{13}, a_{33^{\prime}}, a_{3^{\prime} 1}\right), \\
p_{4}=\left(a_{2}, a_{21}, a_{11^{\prime}}, a_{1^{\prime} 1}\right), & p_{5}=\left(a_{2}, a_{22}, a_{22^{\prime}}, a_{2^{\prime} 1}\right), & p_{6}=\left(a_{2}, a_{23}, a_{33^{\prime}}, a_{3^{\prime} 1}\right),
\end{array}
$$

and for $\mathrm{O} / \mathrm{D}$ pair $w_{2}$ :

$$
\begin{gathered}
p_{7}=\left(a_{1}, a_{11}, a_{11^{\prime}}, a_{1^{\prime} 2}\right), \quad p_{8}=\left(a_{1}, a_{12}, a_{22^{\prime}}, a_{2^{\prime} 2}\right), \quad p_{9}=\left(a_{1}, a_{13}, a_{33^{\prime}}, a_{3^{\prime} 2}\right), \\
p_{10}=\left(a_{2}, a_{21}, a_{11^{\prime}}, a_{1^{\prime} 2}\right), \quad p_{11}=\left(a_{2}, a_{22}, a_{22^{\prime}}, a_{2^{\prime} 2}\right), \quad p_{12}=\left(a_{2}, a_{23}, a_{33^{\prime}}, a_{3^{\prime} 2}\right) .
\end{gathered}
$$

The Euler method converged in 331 iterations and yielded the following equilibrium path flow and travel disutility pattern:

$$
x_{p_{1}}^{*}=x_{p_{2}}^{*}=4.922, \quad x_{p_{3}}^{*}=7.832, \quad x_{p_{4}}^{*}=x_{p_{5}}^{*}=6.448, \quad x_{p_{6}}^{*}=4.396,
$$




$$
x_{p_{7}}^{*}=x_{p_{8}}^{*}=4.937, \quad x_{p_{9}}^{*}=7.813, \quad x_{p_{10}}^{*}=x_{p_{11}}^{*}=6.433, \quad x_{p_{12}}^{*}=4.415,
$$

and

$$
\lambda_{w_{1}}^{*}=\lambda_{w_{2}}^{*}=275.723
$$

The corresponding equilibrium link flows were:

$$
\begin{gathered}
f_{a_{1}}^{*}=35.364 f_{a_{2}}^{*}=34.573, \quad f_{a_{11}}^{*}=f_{a_{12}}^{*}=9.860, \quad f_{a_{13}}^{*}=15.645, \quad f_{a_{21}}^{*}=f_{a_{22}}^{*}=12.881 \\
f_{a_{23}}^{*}=8.811, \quad f_{a_{11^{\prime}}}^{*}=f_{a_{22^{\prime}}}^{*}=22.741, \quad f_{a_{33^{\prime}}}^{*}=24.456 \\
f_{a_{1^{\prime} 1}}^{*}=f_{a_{1^{\prime} 2}}^{*}=f_{a_{2^{\prime} 1}}^{*}=f_{a_{2^{\prime} 2}}^{*}=11.370 \\
f_{a_{3^{\prime} 1}}^{*}=f_{a_{3^{\prime} 2}}^{*}=12.228 .
\end{gathered}
$$

The above results translate into the following equilibrium product shipments and demand market prices on the supply chain network: The product shipments between the two manufacturers and the three retailers were: $Q^{1^{*}}=q_{11}^{*}=q_{12}^{*}=9.860, \quad q_{13}^{*}=15.645, \quad q_{21}^{*}=$ $q_{22}^{*}=12.881, \quad q_{23}^{*}=8.811$, the product shipments between the three retailers and the two demand markets were: $Q^{2^{*}}=q_{11}^{*}=q_{12}^{*}=q_{21}^{*}=q_{22}^{*}=11.370, \quad q_{31}^{*}=q_{32}^{*}=12.228$ and the demand prices at the demand markets were: $\rho_{31}^{*}=\rho_{32}^{*}=275.723$.

Note that the demand prices at the demand markets were now lower than in Example 2 , since there is now an additional retailer and, hence, increased competition. The incurred demand also increased at both demand markets, as did the production outputs of both manufacturers. Since the retailers now handled a greater volume of product shipments, the prices charged for the product at the retailers, nevertheless, increased due to increased handling cost. The above computed values are very close to the analogous ones obtained for Example 3 in Nagurney, Dong, and Zhang (2002).

The above results demonstrate the practical utility of the theoretical results obtained in this paper. 


\section{Summary, Conclusions, and Suggestions for Future research}

This paper demonstrated that a supply chain network equilibrium model from the literature could be reformulated as a transportation network equilibrium model with elastic demands in the case of known demand functions. This identification was made through a supernetwork construction of the former to reveal the transportation network configuration for the supply chain and by showing the variational inequality equivalences of the respective governing equilibrium conditions. In addition, a new interpretation of the supply chain network equilibrium conditions was provided which coincided with the well-known user-optimizing conditions in transportation network equilibrium modeling and analysis.

This connection allows us to transfer the plethora of algorithmic tools developed for transportation networks to the formulation, analysis, and solution of supply chain networks. Moreover, it allows us to transform a spectrum of supply chain network equilibrium models reported in the literature to their corresponding transportation network equilibrium counterparts.

In order to demonstrate the practical usefulness of the theoretical results in this paper, we also applied an algorithm proposed for the solution of transportation network equilibrium problems with elastic demands to compute the equilibrium product shipments and demand market prices for several supply chain network examples taken from the literature, using the supernetwork transformation.

Possible future research may also include: the computation of large-scale supply chain network equilibrium problems with different cost and demand functional forms, with and without the supernetwork equivalence, in order to determine the "most" efficient computational algorithms for such problems; additional supply chain modeling efforts that may include the incorporation of raw material suppliers, distinct production processes, etc., that we expect will be made more transparent using a supernetwork equivalence, as well as the construction of system-optimization analogues for supply chain networks (analogous to those for transportation networks) and the identification of the costs/benefits of competition versus cooperation. 


\section{Acknowledgments}

The research of the author was supported by NSF Grant No.: IIS-0002647. This support is gratefully appreciated.

The author would like to thank the two anonymous reviewers as well as the Editor, Wayne Talley, for helpful comments and suggestions on an earlier version of this paper. 


\section{References}

Aashtiani, M., Magnanti, T. L., 1981. Equilibrium on a congested transportation network. SIAM Journal on Algebraic and Discrete Methods 2, 213-216.

Anupindi, R., Bassok, Y., 1996. Distribution channels, information systems and virtual centralization. In: Proceedings of the Manufacturing and Service Operations Management Society Conference, pp. 87-92.

Bazaraa, M. S., Sherali, H. D., Shetty, C. M., 1993. Nonlinear Programming: Theory and Algorithms. John Wiley \& Sons, New York, 1993.

Beckmann, M. J., McGuire, C. B., Winsten, C. B., 1956. Studies in the Economics of Transportation. Yale University Press, New Haven, Connecticut.

Boyce, D. E., Chon, K. S., Lee, Y. J., Lin, K. T., LeBlanc, L. J., 1983. Implementation and computational issues for combined models of location, destination, mode, and route choice. Environment and Planning A 15, 1219-1230.

Boyce, D. E., Mahmassani, H. S., Nagurney, A., 2004. A retrospective on Beckmann, McGuire, and Winsten's Studies in the Economics of Transportation. To appear in Papers in Regional Science.

Bramel, J., Simchi-Levi, D., 1997. The Logic of Logistics: Theory, Algorithms and Applications for Logistics Management. Springer-Verlag, New York.

Cournot, A. A., 1838, Researches into the Mathematical Principles of the Theory of Wealth. English translation, MacMillan, England.

Dafermos, S., 1980. Traffic equilibrium and variational inequalities. Transportation Science $14,42-54$.

Dafermos, S., 1982. The general multimodal network equilibrium problem with elastic demand. Networks 12, 57-72.

Dafermos, S., 1986. Isomorphic multiclass spatial price and multimodal traffic network 
equilibrium models. Regional Science and Urban Economics 16, 197-209.

Dafermos, S., Nagurney, A., 1984. Stability and sensitivity analysis for the general network equilibrium - travel choice model. In: Volmuller, J., Hamerslag, R. (Eds.), Proceedings of the Ninth International Symposium on Transportation and Traffic Theory. VNU Science Press, Utrecht, The Netherlands, pp. 217-232.

Dafermos, S., Nagurney, A., 1985. Isomorphism between spatial price and traffic network equilibrium problems. LCDS \# 85-17, Lefschetz Center for Dynamical Systems, Brown University, Providence, Rhode Island.

Dafermos, S., Nagurney, A., 1987. Oligopolistic and competitive behavior of spatially separated markets. Regional Science and Urban Economics 17, 245-254.

Dafermos, S. C., Sparrow, F. T., 1969. The traffic assignment problem for a general network. Journal of Research of the National Bureau of Standards 73B, 91-118.

Dong, J., Zhang, D., Nagurney, A., 2004. A supply chain network equilibrium model with random demands. European Journal of Operational Research 156, 194-212.

Dupuis, P., Nagurney, A., 1993. Dynamical systems and variational inequalities. Annals of Operations Research 44, 9-42.

Evans, S., 1976. Derivation and analysis of some models for combining trip distribution and assignment. Transportation Research 10, 37-57.

Federgruen, A., 1993. Centralized planning models for multi-echelon inventory systems under uncertainty. In: Graves, S. C., Rinooy Kan, A. H. G., Zipkin, P. (Eds.), Handbooks in Operations Research and Management Science, Volume on Logistics of Production and Inventory. Elsevier Science, Amsterdam, The Netherlands, pp. 133-173.

Federgruen, A., Zipkin, P., 1986. An inventory model with limited production capacity and uncertain demands I: The average cost criterion. Mathematics of Operations Research 11, 193-207. 
Fisk, C., Boyce, D. E., 1983. Alternative variational inequality formulation of the network equilibrium-travel choice problem. Transportation Science 17, 454-463.

Florian, M., Hearn, D., 1995. Network equilibrium models and algorithms. In: Ball, M. O., Magnanti, T. L., Monma, C. L., Nemhauser, G. L. (Eds.), Network Routing, Handbooks in Operations Research and Management Science 8. Elsevier Science, Amsterdam, The Netherlands, pp. 485-440.

Ganeshan, R., Jack, E., Magazine, M. J., Stephens, P., 1998. A taxonomic review of supply chain management research. In: Tayur, S., Magazine, M., Ganeshan, R. (Eds.), Quantitative Models for Supply Chain Management. Kluwer Academic Publishers, Boston, Massachusetts, 531-574.

Hensher, D., Button, K., Brewer, S. (Eds.), 2001. Handbook of Logistics and Supply Chain Management. Elsevier Science, Oxford, England.

Kohl, J. E., 1841. Der verkehr und die ansiedelungen der menschen in ihrer abhangigkeit von der gestaltung der erdorberflache. Dresden, Leipzig, Germany.

Korpelevich, G. M., 1977. The extragradient method for finding saddle points and other problems. Matekon 13, 35-49.

Lederer, P. J., Li, L., 1997. Pricing, production, scheduling, and delivery-time competition. Operations Research 4, 407-420.

Lee, L., Billington, C., 1993. Material management in decentralized supply chains. Operations Research 41, 835-847.

Mentzer, J. T. (Ed.), 2001. Supply Chain Management. Sage Publishers, Thousand Oaks, California.

Miller, T. C., 2001. Hierarchical Operations and Supply Chain Planning. Springer-Verlag, London, England.

Nagurney, A., 1999. Network Economics: A Variational Inequality Approach, second and 
revised edition. Kluwer Academic Publishers, Dordrecht, The Netherlands.

Nagurney, A., 2000. Sustainable Transportation Networks. Edward Elgar Publishing, Cheltenham, England.

Nagurney, A., Dong, J., 2002. Supernetworks: Decision-Making for the Information Age. Edward Elgar Publishing, Cheltenham, England.

Nagurney, A., Dong, J., Zhang, D., 2002. A supply chain network equilibrium model. Transportation Research E 38, 281-303.

Nagurney, A., Loo, J., Dong, J., Zhang, D., 2002. Supply chain networks and electronic commerce: A theoretical perspective. Netnomics 4, 187-220.

Nagurney, A., Matsypura, D., 2004. A supply chain network perspective for electric power generation, supply, transmission, and consumption. In: Proceedings of the International Conference in Computing, Communications and Control Technologies, Austin, Texas, Volume VI, pp. 127-134.

Nagurney, A., Toyasaki, F., 2005. Reverse supply chain management and electronic waste recycling: A multitiered network equilibrium framework for e-cycling. Transportation Research E 41, 1-28.

Nagurney, A., Zhang, D., 1996. Projected Dynamical Systems and Variational Inequalities with Applications, Kluwer Academic Publishers, Boston, Massachusetts.

Nash, J. F., 1959. Equilibrium points in n-person games. Proceedings of the National Academy of Sciences, USA 36, 48-49.

Nash, J. F., 1951. Noncooperative games. Annals of Mathematics 54, 286-298.

Patriksson, M., 1994. The Traffic Assignment Problems - Models and Methods. VSP, Utrecht, The Netherlands.

Pigou, A. C., 1920. The Economics of Welfare. Macmillan, London, England. 
Samuelson, P. A., 1952. Spatial price equilibrium and linear programming. American Economic Review 42, 293-303.

Slats, P. A., Bhola, B., Evers, J. J., Dijkhuizen, G., 1995. Logistic chain modelling. European Journal of Operations Research 87, 1-20.

Smith, M. J., 1979. Existence, uniqueness, and stability of traffic equilibria. Transportation Research 13B, 259-304.

Stadtler, H., Kilger, C. (Eds.), 2000. Supply Chain Management and Advanced Planning. Springer-Verlag, Berlin, Germany.

Takayama, T., Judge, G. G., 1971. Spatial and Temporal Price and Allocation Models. North-Holland, Amsterdam, The Netherlands.

Wardrop, J. G., 1952. Some theoretical aspects of road traffic research. In: Proceedings of the Institution of Civil Engineers, Part II 1, 325-378.

Zhang, D., Dong, J., Nagurney, A., 2003. A supply chain network economy: Modeling and qualitative analysis. In: Nagurney, A. (Ed.), Innovations in Financial and Economic Networks. Edward Elgar Publishing, Cheltenham, England, pp. 198-313. 